\title{
Multispectral and colour imaging systems for the detection of small vertebrate fossils: A preliminary study
}

\author{
Xana Delpueyo, Meritxell Vilaseca, Marc Furió, \\ Francisco J. Burgos-Fernández, and Jaume Pujol
}

\begin{abstract}
The process of separating small vertebrate fossils from sediment is a monotonous exercise, usually carried out manually and mainly based on morphological features. The large amount of time and personnel required results in the high economic costs associated with this antiquated technique. In this study we test the potential of colour and multispectral imaging for the detection of small vertebrate fossils to facilitate their separation from sediment. This technique is based on the analysis of the spectral and fluorescence characteristics of fossils. Specifically, a multispectral system with a charge-coupled device (CCD) camera attached to a liquid crystal tunable filter and a digital colour camera was used in combination with daylight and ultraviolet light sources. The results show that the reflectance of bones, teeth and sediment are usually different at longer wavelengths, and that fluorescence rates also differ in the bluegreen region. Unfortunately, samples from different paleontological sites present different patterns, hindering the standardization of a method that discriminates microfossils from sediments. However, the combination of colour and multispectral imaging systems with recent advances in laser-stimulated fluorescence in fossils could constitute an optimal solution for an efficient sorting process of small vertebrate remains within geological samples.
\end{abstract}

Xana Delpueyo. Centre for Sensors, Instruments and Systems Development (CD6), Universitat Politècnica de Catalunya (UPC) (Rambla Sant Nebridi 10, 08222-Terrassa, Barcelona, Spain).

xana.delpueyo@upc.edu

Meritxell Vilaseca. Centre for Sensors, Instruments and Systems Development (CD6), Universitat Politècnica de Catalunya (UPC) (Rambla Sant Nebridi 10, 08222-Terrassa, Barcelona, Spain)

mvilasec@oo.upc.edu

Marc Furió. Institut Català de Paleontologia M. Crusafont, Universitat Autònoma de Barcelona (UAB)

(Edifici ICP, c/ de les Columnes s/n, Campus de la UAB, 08193-Cerdanyola del Vallès, Barcelona, Spain)

marc.furio@icp.cat

Francisco J. Burgos-Fernández. Centre for Sensors, Instruments and Systems Development (CD6), Universitat Politècnica de Catalunya (UPC) (Rambla Sant Nebridi 10, 08222-Terrassa, Barcelona, Spain) francisco.javier.burgos@upc.edu

Jaume Pujol. Centre for Sensors, Instruments and Systems Development (CD6), Universitat Politècnica de Catalunya (UPC) (Rambla Sant Nebridi 10, 08222-Terrassa, Barcelona, Spain) pujol@oo.upc.edu

Delpueyo, Xana, Vilaseca, Meritxell, Furió, Marc, Burgos-Fernández, Francisco J., and Pujol, Jaume. 2016. Multispectral and colour imaging systems for the detection of small vertebrate fossils: A preliminary study. Palaeontologia Electronica 19.3.5T: 1-9 palaeo-electronica.org/content/1624-multispectral-detection 
Keywords: multispectral systems; fluorescence; fossil separation system

Submission: 2 February 2016 Acceptance: 20 September 2016

\section{INTRODUCTION}

Small vertebrate fossils have several applications in palaeontology, particularly in the fields of continental biostratigraphy and paleoecology. However, their small dimensions preclude the use of excavation techniques typically employed in largevertebrate localities. Usually, the recovery of these fossils involves water-screening tones of sediment that result in large quantities of sand with scattered small bones and teeth. The separation of fossils from the sediment is carried out by hand following the criteria of external morphology. Consequently, the amount of time that this process requires has a significant impact on the budget of many research projects.

The process of wet sieving in Europe was improved in the 1970s with the introduction of highpressure water and the incorporation of a variety of mesh sizes (Daams and Freudenthal, 1988). This methodological development significantly reduced the time needed to remove clay particles and decreased the loss of useful material in many paleontological sites. However, the techniques of small fossil detection and their physical separation remain the same. According to Daams and Freudenthal (1988), a week is required to process a $100 \mathrm{~kg}$ sample of sediment. Assuming a similar rate, samples of $1000 \mathrm{~kg}$ or $5000 \mathrm{~kg}$ would require two months to one year of full-time work by a professional. This lengthy process has created a 'bot-

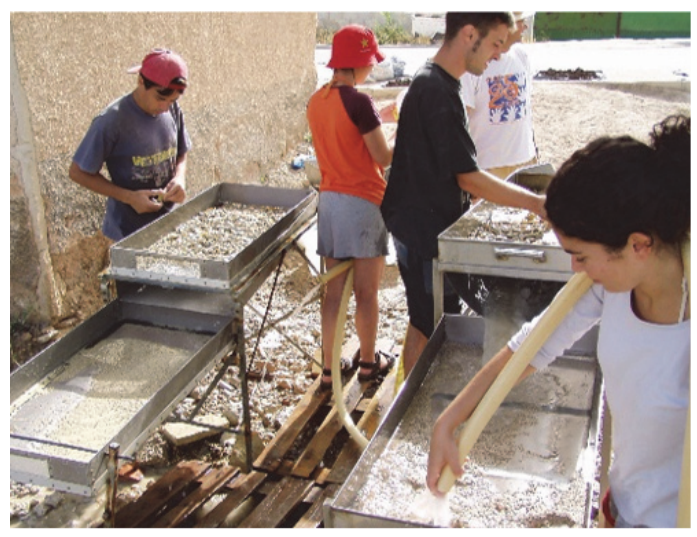

1 tle-neck effect' by which large volumes of sediment remain stored in museums and universities waiting for a trained specialist to separate the relevant particles through visual recognition under a binocular microscope (Van den Hoek Ostende, 2003) (Figure 1). Indeed, the manual operation still restricts the process due to the great amount of time and human resources needed (Sala-Burgos and GilPita, 2006).

Preliminary attempts at the detection of fossils have been made using Multilayer Perceptrons to discriminate fossil teeth from mineral grains (SalaBurgos and Gil-Pita, 2006). Other investigators have exploited the fluorescent properties that some fossils exhibit under ultraviolet (UV) radiation, which enhance the distinction of bones and teeth from other components like sand and gravel (Croft et al., 2004). However, this method cannot be universally used since fluorescence properties depend on the type of fossils analysed and limits of light exposure exist in relation to the preservation of paleontological remains. To circumvent this last aspect, Kaye and colleagues (Kaye et al., 2015) recently explored the possibilities of laser stimulation to enhance the fluorescent properties of fossils and developed the prototype of an automated micro-fossil picker (Kaye et al., 2015, figure 10). However, further research is still needed with regard to the spectral features of different types of fossils to overcome some of the limitations in fossil detection.

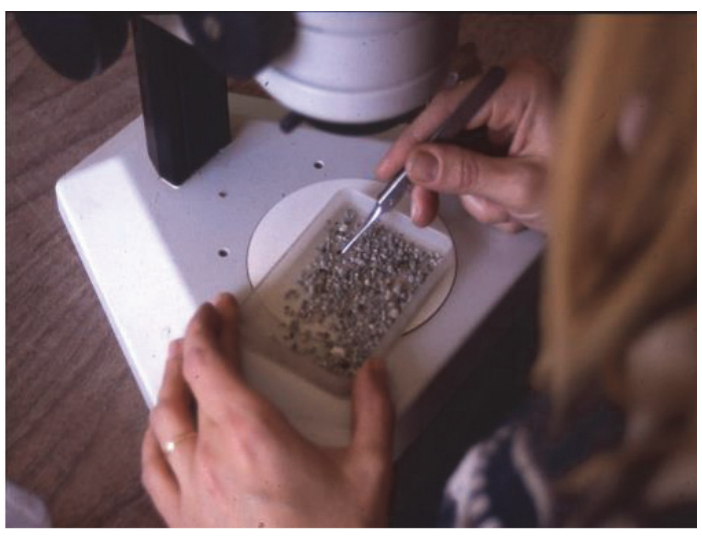

2

FIGURE 1. 1, Wet sieving process of palaeontological samples using Freudenthal's technique. 2, Visual recognition and separation of teeth and bones using a binocular microscope and pincers. 
In this context, multispectral imaging systems, which combine a spectral sampling technique with a digital imaging sensor, can provide better results. Multispectral imaging systems measure spectral properties with a high spatial resolution that enables the individual and independent analysis of minute samples, generally below $2 \mathrm{~mm}$ in size. These systems solve some limitations of standard spectrometers based on single detectors for the study of samples that are not uniform.

Various methods can carry out the spectral sampling in multispectral systems; these include single point spectrometers together with 2-D scanning systems (Bonifazzi et al., 2008), digital cameras combined with line-scan spectrographs known as pushbroom systems (Barbin et al., 2012) and imaging systems that incorporate filters in the optical path. This last approach is achieved through colour filter wheels (Vilaseca et al., 2006) and tunable filters of liquid crystal or acousto-optic technology (Hardeberg et al., 2002; Tran, 2005). Multispectral imaging is a recent field of research with many applications such as remote sensing (Weng, 2011), colour imaging (Shrestha et al., 2011), biometrics and medicine (Vilaseca et al., 2008; Paquit et al., 2009; Bouchard et al., 2009; Basiri et al., 2010; Everdell et al., 2010), cultural heritage, and art work studies (Kubik, 2007; Padoan et al., 2008; Marengo et al., 2011; HerreraRamírez et al., 2014). However, its use in palaeontology has been anecdotal, with only one brief reference on its application on fake-fossil detection (Kaye et al., 2010). In this article we demonstrate the feasibility of using colour and multispectralbased imaging methods to improve the separation of fossil bones and teeth from sediment.

\section{METHODS}

Samples from three different fossil sites from Catalonia, Spain were analysed. Sample 1 is from Abocador de Can Mata C5-D1 (Hostalets de Pierola; Vallès-Penedès Basin, Barcelona, NE Spain), a Middle Miocene locality with an age of 11.6 Ma (Furió et al., 2015); Sample 2 is from Sant Jaume de Frontanyà 3 (Eastern Pyrenees, Barcelona, NE Spain), the most significant middle Eocene fossil site from the Iberian Peninsula (Minwer-Barakat et al., 2010; Marigó et al., 2011), with an approximate age of $40 \mathrm{Ma}$ (Vandenberghe et al., 2012); and Sample 3 is from Can Llobateres 1 (Sabadell; Vallès-Penedès Basin, Barcelona, NE Spain), the reference location for the Vallesian continental stage (Late Miocene) in Europe, with an age of $9.78 \mathrm{Ma}$ (Casanovas-Vilar et al., 2011, 2014).

These fossil sites were selected according to the following criteria: 1) more than one tone of sediment has been processed, so that the loss of a small part should not have a significant impact; 2) the fossil material was relatively abundant (hundreds of small bones or fragments and teeth per kilogram of sediment), so that the fossil elements could easily cover one $\mathrm{cm}^{2}$ several $\mathrm{mm}$ thick for the correct illumination and multispectral analyses of the sample; 3 ) the properties of the samples were considerably different to maximize the range of types of fossilization and geological conditions in order to test the broad applicability of the technique.

Each sample was divided in two parts. The first was separated by one of the researchers (MF), who manually picked bones and teeth from the sediment, and the second remained unsorted. The parts that included only small bones and teeth were analysed first. These samples were characterized by means of a single point commercial spectrometer (Instrument Systems $®$ Spectro 320 Scanning) with a telescopic optical probe for radiance measurements (Top100 accessory) in the visible range (380 $\mathrm{nm}$ to $780 \mathrm{~nm}$ with a $10 \mathrm{~nm}$-step) over an area approximately $5 \mathrm{~mm}$ in diameter. A uniform overhead luminaire (SpectraLight III) was used to irradiate the samples using $D$ (diffuse) $/ 0^{\circ}$ instrument geometry. Measurements of spectral reflectance were performed under daylight (D65) using a calibrated white plate (Gigahertz-Optik's BN-R98-SQ12, $254 \times 254 \mathrm{~mm}$ ) for comparison. The emission spectra of the samples in terms of radiance $\left(\mathrm{W} / \mathrm{sr} \cdot \mathrm{cm}^{2}\right)$ was also measured under UV illumination (filtered near UV - SpectraLight III), which is similar to the amount of UV found in natural daylight and used to simulate the effects of optical brighteners and fluorescent whitening agents on colour. Spectral data allowed us to detect spectral differences between the microfossils and the sand-gravel by highlighting wavelength peaks or ranges that could help discriminate between them.

Spectral images of the samples were also acquired with a multispectral imaging system comprising a 12 bit-depth monochromatic camera (QImaging QICAM Fast 1394) and a liquid crystal tunable filter (LCTF) (Varispec filter model \#VIS07-HC-20-1012) under daylight (D65) (SpectraLight III overhead luminaire) (Figure 2). The system allowed us to obtain images in 33 different spectral bands (from $400 \mathrm{~nm}$ to $720 \mathrm{~nm}$ with a 10 nm-step). The exposure time for each spectral 


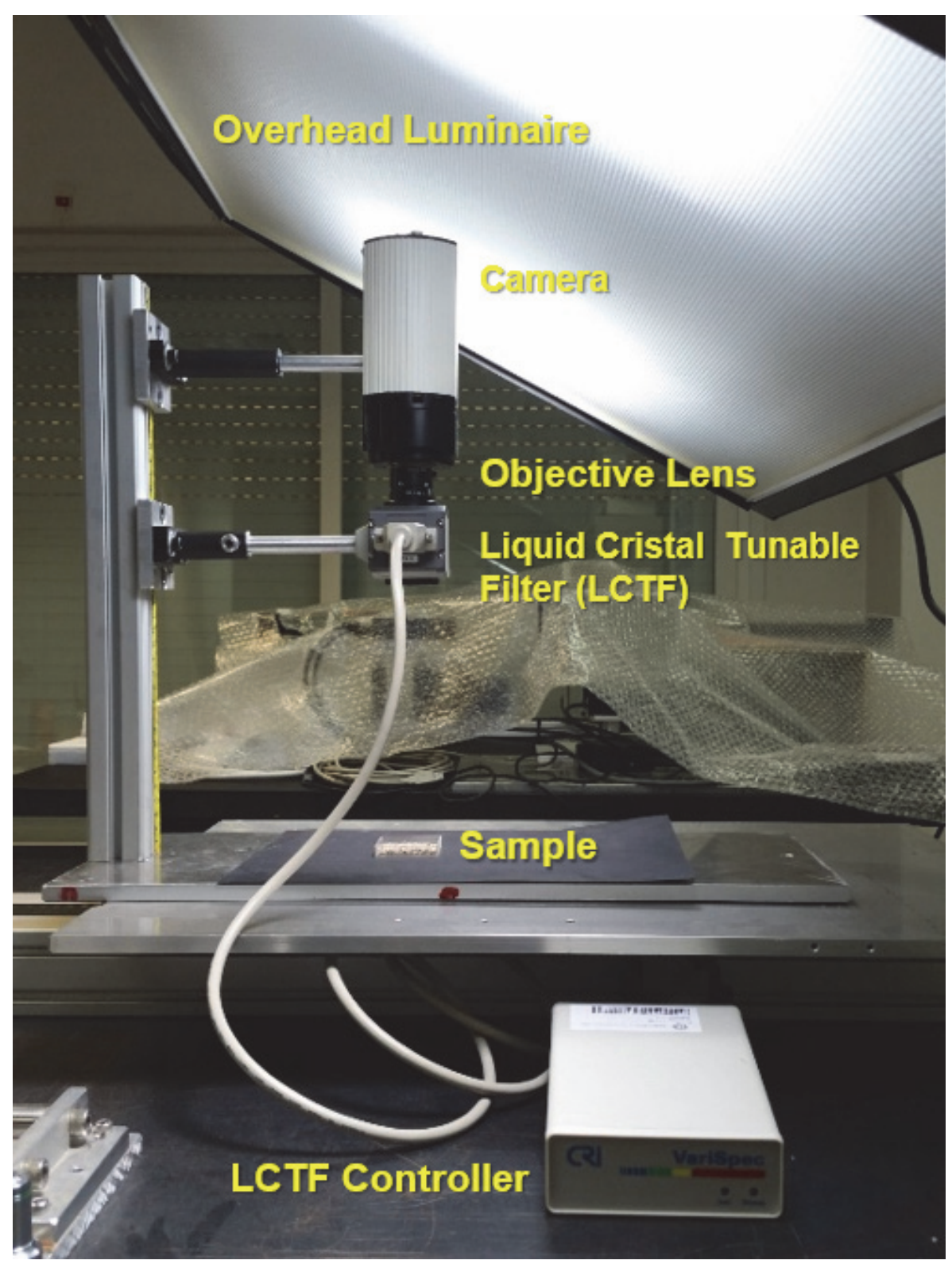

FIGURE 2. Experimental multispectral imaging system.

band was adjusted to optimize the dynamic range of the camera for all of them. Due to the low sensitivity of the former system it was not possible to acquire spectral images of the samples when they were illuminated with UV light. Instead, a conventional digital colour camera (Pentax Optio VS20) was used to acquire RGB images of the samples under UV and D65 lighting conditions.

Both the spectral and colour images allowed us to have spectral, colour, and fluorescence information of the samples with a high spatial resolution, i.e., pixel by pixel, facilitating the distinction between fossils and sediment.
Finally, images from samples containing a mixture of microfossils and sand-gravel were obtained under D65 and UV light, as a means of studying different strategies based on image processing and subsequent segmentation to allow a faster detection and later separation.

\section{RESULTS}

\section{Sample 1}

Figure 3.1 shows the mean spectral reflectance of the microfossils and the sand-gravel samples in the visible range of the electromagnetic spectrum. Here, bones and teeth have higher 

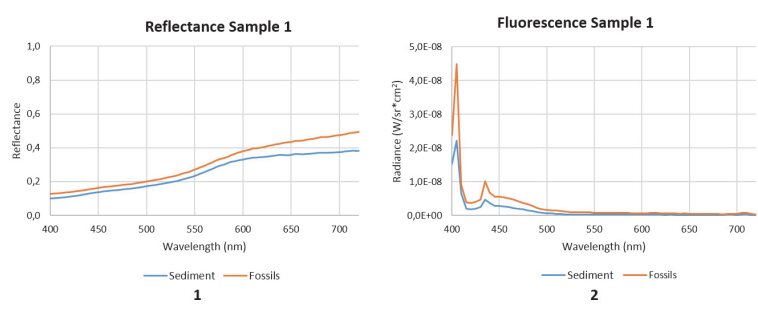

FIGURE 3. 1, Reflectance spectra of sediment (sand and gravel) and fossils (bones and teeth) of Sample 1. 2, Fluorescence spectra (radiance in W/sr $\cdot \mathrm{cm}^{2}$ ) of sediment (sand and gravel) and fossils (bones and teeth) of Sample 1.

reflectance values and this difference increases at longer wavelengths. In Figure 3.2, the fluorescence spectra measured when the samples are illuminated with UV light show that fossils are linked to a larger emission. However, no specific peaks allow distinction between them. On the other hand, microfossils also present a more marked fluorescence rate than sand-gravel samples, essentially from $400 \mathrm{~nm}$ to $500 \mathrm{~nm}$.

The increased difference in reflectance at longer wavelengths can also be observed in Figure 4.1 , which shows some of the spectral images taken with the multispectral system under D65 illumination, together with the RGB image computed from the individual spectral bands by means of the sRGB - standard RGB colour space (IEC 61966-21:1999/AMD1:2003). The luminous differences achieved at wavelengths of $600 \mathrm{~nm}$ or more make them more suitable to detect the fossil remains from sediment. It should be emphasized that the RGB image does not provide the marked difference between samples of the spectral images at long wavelengths. Assuming that the RGB image is similar to what the naked eye can see, we suggest that the use of spectral images at specific wavelengths can easily detect the interesting particles for their later separation from the sample.

Colour images under D65 and UV illumination conditions of the paleontological remains including mixed samples, i.e., with microfossils and sandgravel together, are shown in Figure 5. While it is practically impossible to differentiate between samples using the daylight image, UV light enhances the contrast between bones, teeth, and sediment thanks to spectral differences in the emission of fluorescence, especially in the blue-green region. Accordingly, the blue and green components of the RGB image under UV light can be used to obtain maximum enhanced contrast between the bones, teeth and sediment. Due to the high signal in the

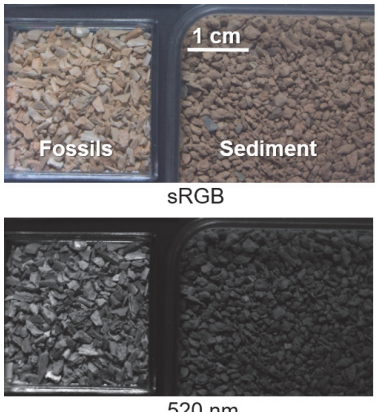

$520 \mathrm{~nm}$

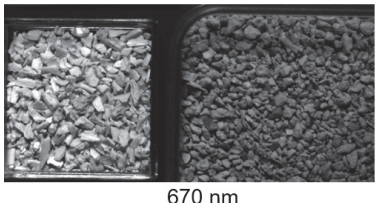

$670 \mathrm{~nm}$

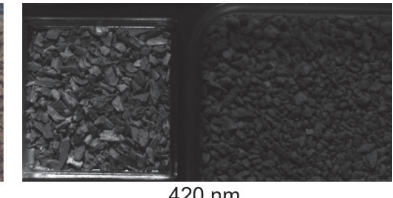
$420 \mathrm{~nm}$

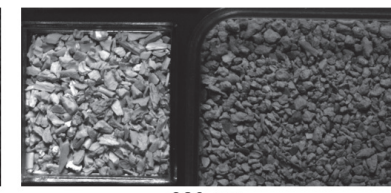

$620 \mathrm{~nm}$

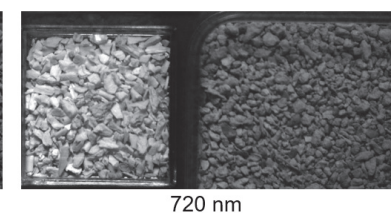

FIGURE 4. Examples of spectral images of Sample 1 through spectral bands $(420,520,620,670$, and 720 $\mathrm{nm}$ ) taken under daylight. An RGB image computed using the $\mathrm{SRGB}$ - standard RGB colour space is also provided.

blue channel image, which saturates some of the microfossils, the green component appears to be the best option in this case. A later image processing procedure of this channel, which includes a segmentation algorithm, allows the easy separation of fossils from sand and gravel sediment, as shown in Figure 5.5. The algorithm is based on a thresholding method applied to the intensity histogram of the image which enhances the subtle differences of fluorescence between the fossils and the sediment. This is achieved through a contrast adjustment of the image by linearly scaling the pixel values between upper and lower limits. Pixel values that are above or below this range are saturated to the upper or lower limit value, respectively. The results obtained indicate that this procedure can be used to detect fossils and later separate them.

\section{Sample 2}

This sample was separated into three different components: sediment, reddish ferrous particles, and fossils. Figure 6 shows the mean reflectance of the different elements and their corresponding fluorescence emission. In this case, inorganic sediment grains and fossils have a similar and low spectral reflectance pattern, and all of them acquire a dark appearance. Only in the case of the ferrous particles are slightly lighter images obtained at longer wavelengths, whereas fossils and sediment remain dark. This is verified in Figure 7 , which shows the spectral images through several spec- 

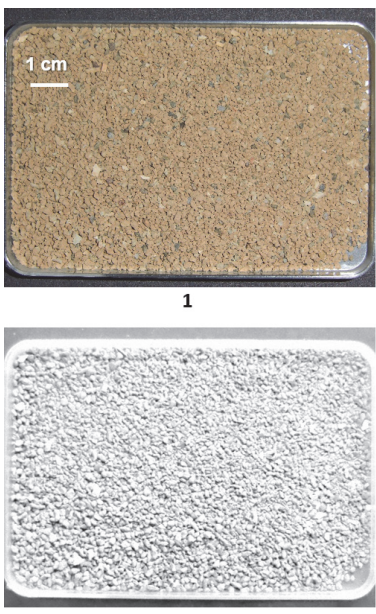

3
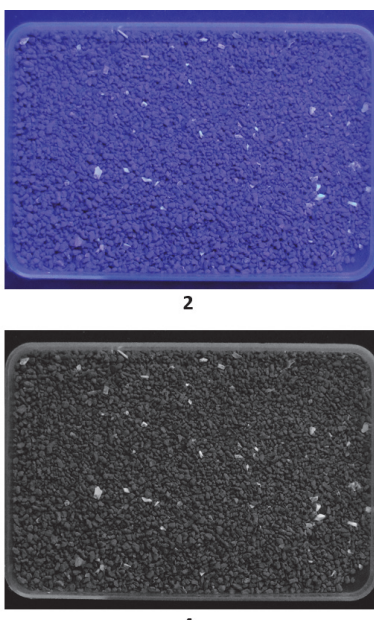

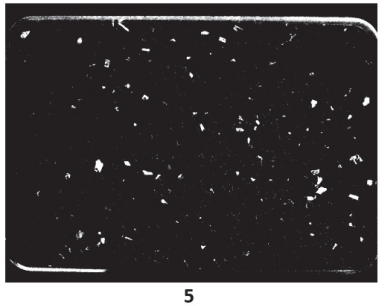

FIGURE 5. Mixture of bones-teeth and sand-gravel from Sample 1. 1, RGB image under daylight (D65). 2, RGB image under UV light. 3, Blue channel image under UV light. 4, Green channel image (grayscale) under UV light. $\mathbf{5}$, Black and white image after segmentation of the green channel image.

tral bands of the multispectral imaging system. Ferrous particles are the only components that change their appearance with wavelength. More specifically, they appear lighter in the red region.

With regard to fluorescence, no differences are found among the components of this sample (Figure 6.2). Similarly, even if the sample is illuminated with UV light, it is not possible to enhance the contrast between microfossils and sediment
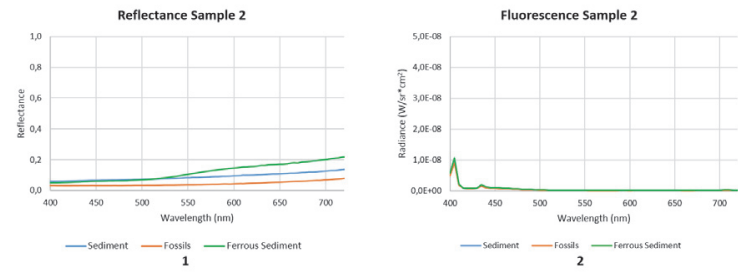

FIGURE 6. 1, Reflectance spectra of sediment (sand and gravel), fossils (bones and teeth) and ferrous sediment of Sample 2. 2, Fluorescence spectra (radiance in $\mathrm{W} / \mathrm{sr}^{*} \mathrm{~cm}^{2}$ ) of sediment (sand and gravel), fossils (bones and teeth) and ferrous sediment of Sample 2.

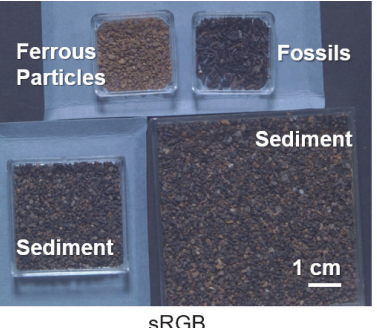

sRGB

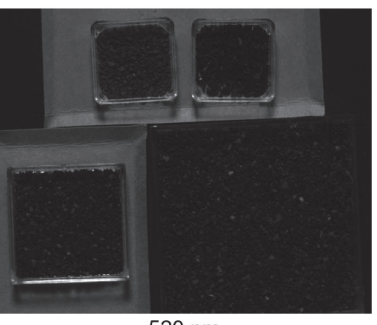

$520 \mathrm{~nm}$

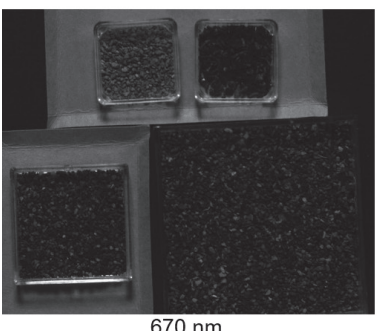

$670 \mathrm{~nm}$

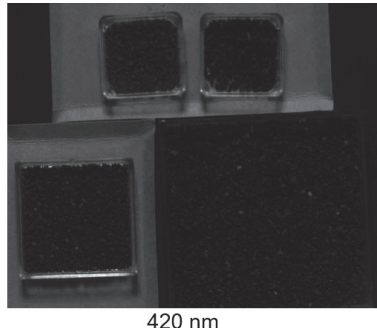

$420 \mathrm{~nm}$

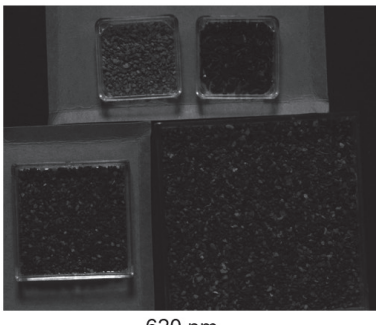

$620 \mathrm{~nm}$

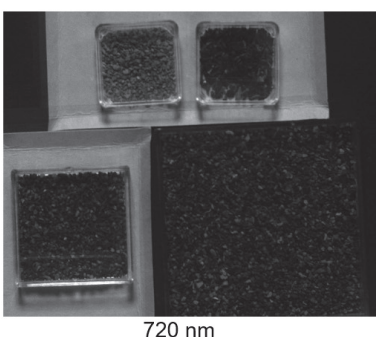

$720 \mathrm{~nm}$
FIGURE 7. Examples of spectral images of Sample 2 through spectral bands $(420,520,620,670$ and 720 $\mathrm{nm}$ ) taken under daylight. An RGB computed using the sRGB - standard RGB colour space image is also provided.

(Figure 8). Since no differences of reflectance and fluorescence were found, no algorithm to highlight the spectral differences could be applied.

\section{Sample 3}

Sample 3 consists of fossils and sediment with a great variety of components, giving a nonuniform appearance to this sample. Figure 9 shows the mean reflectance of sediment and fossils as well as the fluorescence emission when sediment and fossils were separated manually. The sediment appears much lighter than fossils along the visible range (Figure 10), however, the various types of sediment in this sample make it difficult to distinguish between fossils and sediments with the naked eye.

In contrast, when the sample is illuminated with UV light, spectral differences between the sediment and the microfossils become evident. Unexpectedly, in this sample sediments present more marked fluorescence in the blue-green region $(400$ to $500 \mathrm{~nm}$ ) than fossils (Figure 9.2). The blue 

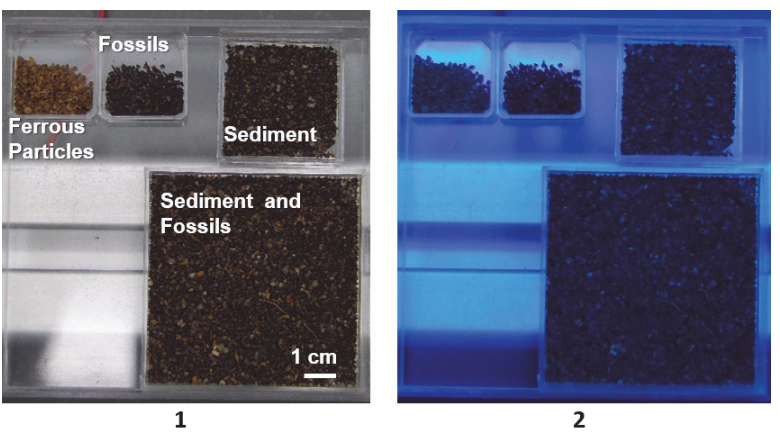

FIGURE 8. RGB images of Sample 2 with ferrous particles, bones-teeth, sand-gravel and a mixture of bonesteeth and sand-gravel. 1, Under daylight (D65). 2, Under UV Light.

component of the RGB image was selected in this case to implement the same thresholding method than in Sample 1. This image was used because of the highest contrast between microfossils and sediments (Figure 11). The results show that the identification of fossil remains is easier over the segmented image (Figure 11.4).

\section{CONCLUSIONS}

In two of the three samples analysed using novel colour and multispectral imaging systems, the various spectral patterns for fossils and sediments indicate that this is a useful technique for automating the process of detection and subsequent separation. Different patterns of fluorescence between microfossils and sand-gravel samples emerged when segmentation algorithms based on thresholding methods were applied on the green or blue channel images taken under UV light. However, no contrast was observed in one of
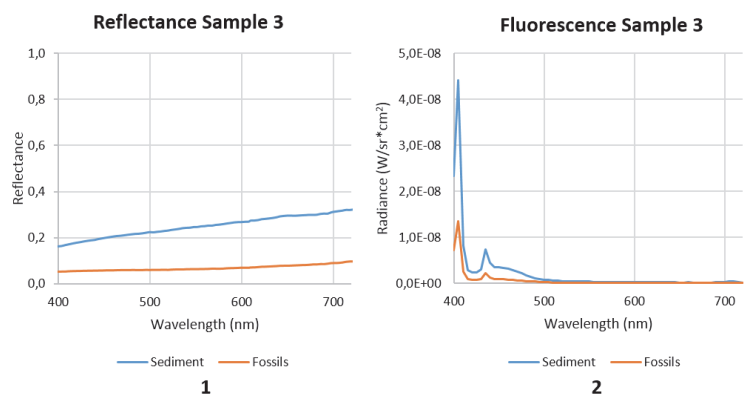

FIGURE 9. 1, Reflectance spectra of sediment (sand and gravel) and fossils (bones and teeth) of Sample 3. 2, Fluorescence spectra (radiance in W/sr* $\mathrm{cm}^{2}$ ) of sediment (sand and gravel) and fossils (bones and teeth) of Sample 3.
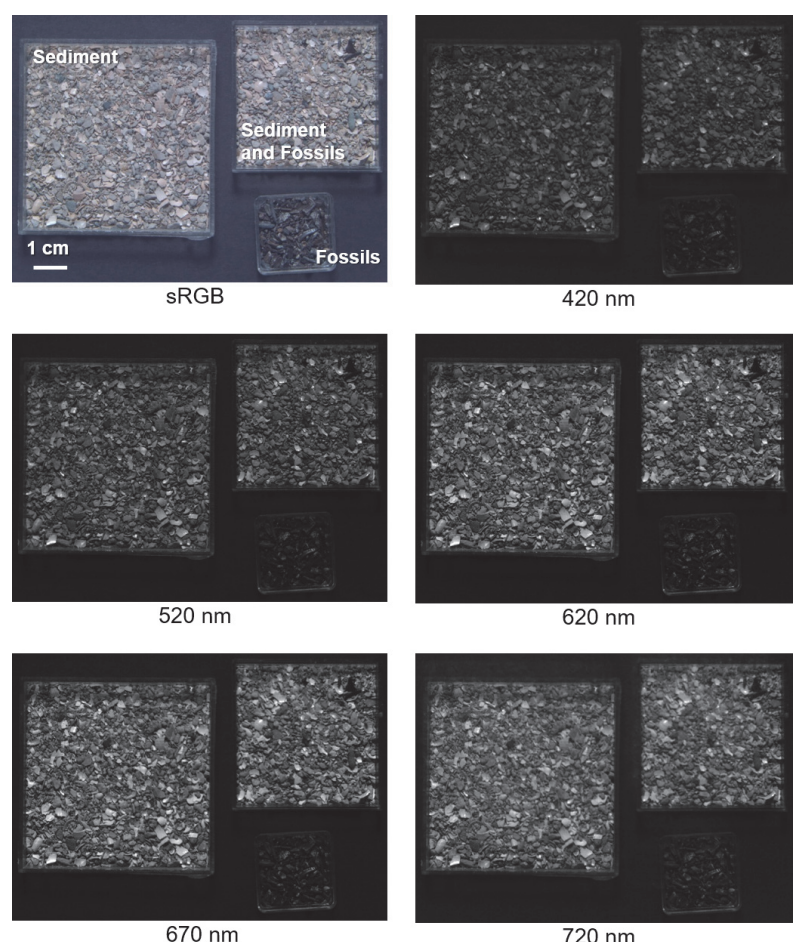

$720 \mathrm{~nm}$

FIGURE 10. Examples of spectral images of Sample 3 through spectral bands $(420,520,620,670$, and 720 $\mathrm{nm}$ ) taken under daylight. An RGB computed using the sRGB - standard RGB colour space image is also provided.

the samples between the spectral features of sediment and fossils.

Consequently, although novel colour and multispectral imaging systems can be successfully applied to enhance the contrast between fossils and sediments in many samples, this technique cannot be standardized for use in all types of samples. An improved method might be obtained with the combination of this technique with the new advances on laser-stimulated fluorescence in fossils (Kaye et al., 2015).

Laser-stimulated fluorescence utilizes laser illumination instead of standard UV light resulting in detectable fluorescence of many hard-to-fluoresce mineral types, which typically remain dark under standard UV. Furthermore, with laser it is possible to match the correct wavelength with one of the specimen's absorption bands thus providing more effective excitation of fluorescence in a sample. Since laser is very bright, a specialized light-blocking longpass optical filter that matches one of the fluorescence bands of the specimen can be used to improve contrast in the fluorescence image. This system would still allow the longer wave fluorescence signal to pass through. For instance, a red- 


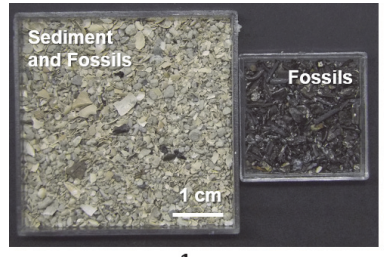

1
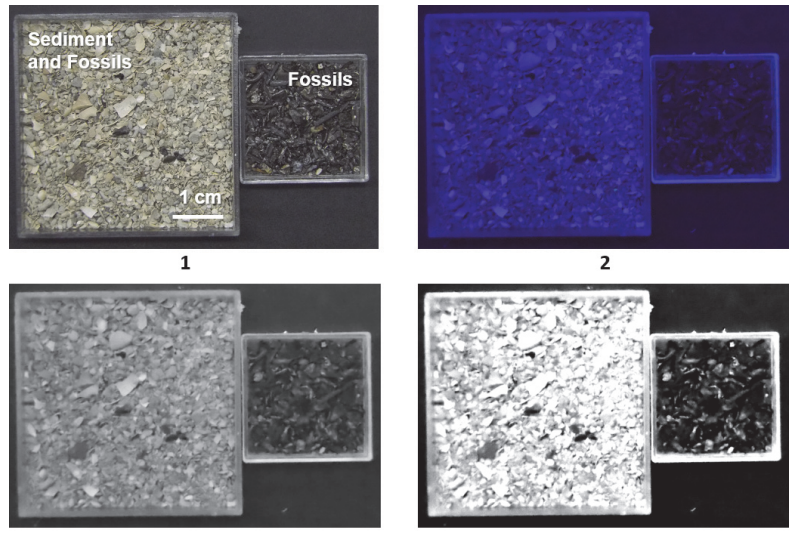

3

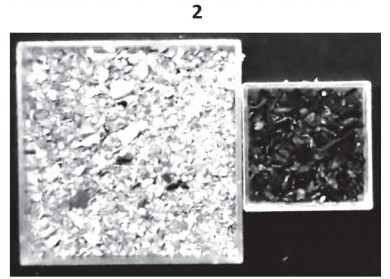

FIGURE 11. Fossils (bones and teeth) and a mixture of fossils and sediment (sand and gravel) from Sample 3. 1, RGB image under daylight (D65). 2, RGB image under UV light. 3, Blue channel image (grayscale) under UV light. 4, Black and white image after segmentation of the blue channel image.

orange longpass filter with high transmission from $600 \mathrm{~nm}$ to $1100 \mathrm{~nm}$ in combination with a $477 \mathrm{~nm}$ blue laser for stimulation could be used for such purpose.

The optical filter could be replaced by a multispectral imaging system since its transmission can be tuned along the visible range. Accordingly, the wavelength of the laser used to stimulate fluorescence should be avoided, and only images from longer wavelengths would be acquired with the multispectral system in which the signal-to-noise ratio would also be improved.

The combination of the systems and the subsequent analysis of its spectral information can transform palaeontological methods by decreasing the time and economic costs of differentiating small vertebrate fossils from sediment.

Further research is still needed to gain a better understanding of the reflectance and fluorescence properties of paleontological remains and to elucidate how the combination of such techniques can be used to automate the process of detection and posterior separation of fossils.

\section{ACKNOWLEDGEMENTS}

This research was supported by the Spanish Ministry for Economy and Competitiveness (Grant DPI2011-30090-C02-01 and CGL2015-63777-P), the AGAUR of the Generalitat de Catalunya (Grants 2014SGR1123 and 2014 SGR 416 GRC), and the European Union. The Culture Department of the Generalitat de Catalunya further supported this study with the projects 2014/100604 and 2014/
100609. Xana Delpueyo would like to thank the Terrassa City Council for the Research Grant for University Students, Call 2013, she was awarded. We would also like to thank the European Colour and Space in Cultural Heritage $(\mathrm{COSCH}) \mathrm{COST}$ action for their financial support to some research visits and meetings. David M. Alba and Raef Minwer-Barakat (ICP) kindly provided the geological samples analysed in this study and recommended bibliography related to these sites.

\section{REFERENCES}

Barbin, D.F., Elmasry, G., Sun, D.W., and Allen, P. 2012. Predicting quality and sensory attributes of pork using near-infrared hyperspectral imaging. Analytica Chimica Acta, 719:30-42.

doi:10.1016/j.aca.2012.01.004.

Basiri, A., Nabili, M., Mathews, S., Libin, A., Groah, S., Noordmans, H.J., and Ramella-Roman, J.C. 2010. Use of a multi-spectral camera in the characterization of skin wounds. Optics express, 18:3244-3257. Retrieved from www.ncbi.nlm.nih.gov/pubmed/ 20389332.

Bonifazzi, C., Carcagnì, P., Fontana, R., Greco, M., Mastroianni, M., Materazzi, M., Pampaloni, E., Pezzati, L., and Bencini, D. 2008. A scanning device for VISNIR multispectral imaging of paintings. Journal of Optics A: Pure and Applied Optics, 10:064011. doi:10.1088/1464-4258/10/6/064011.

Bouchard, M.B., Chen, B.R., Burgess, S.A., and Hillman, E.M.C. 2009. Ultra-fast multispectral optical imaging of cortical oxygenation, blood flow, and intracellular calcium dynamics. Optics express, 17:15670-15678. Retrieved from www.pubmedcentral.nih.gov/articlerender.fcgi?artid=2760073\&tool=pmcentrez\&rendertype=abstract.

Casanovas-Vilar, I., Alba, D.M., Garcés, M., Robles, J.M., and Moyà-Solà, S. 2011. Updated chronology for the Miocene hominoid radiation in Western Eurasia. Proceedings of the National Academy of Sciences, 108(14):5554-5559.

doi: $10.1073 /$ pnas.1018562108.

Casanovas-Vilar, I., van den Hoek Ostende, L.W., Furió, M., and Madern, P.A. 2014. The range and extent of the Vallesian Crisis (Late Miocene): newprospects based on the micromammal record from the VallèsPenedèsbasin (Catalonia, Spain). Journal of Iberian Geology 40(1):29-48. dx.doi.org/10.5209/rev_JIGE.2014.v40.n1.44086

Croft, D., Kaye, T., and Panko, L. 2004. A new method for finding small vertebrate fossils: ultraviolet light at night. Palaeontology, 47:795-800. Retrieved January 9, 2014, from doi/10.1111/j.0031-0239.2004.00398.x/full.

Daams, R. and Freudenthal, M. 1988. Synopsis of the Dutch-Spanish collaboration program in the Aragonian type area , 1975-1986. Scripta Geologica, 3-18. 
Everdell, N.L., Styles, I.B., Calcagni, A., Gibson, J., Hebden, J., and Claridge, E. 2010. Multispectral imaging of the ocular fundus using light emitting diode illumination. The Review of scientific instruments, 81. doi:10.1063/1.3478001.

Furió, M., Prieto, J., and van den Hoek Ostende, L.W. 2015. Three million years of "Terror-Shrew" (Dinosorex, Eulipotyphla, Mammalia) in the Miocene of the Vallès-Penedès Basin (Barcelona, Spain). Comptes Rendus Palevol, 14:111-124. Academie des sciences. doi:10.1016/j.crpv.2014.12.001.

Hardeberg, J.Y., Schmitt, F., and Brettel, H. 2002. Multispectral color image capture using a liquid crystal tunable filter. Optical Engineering, 41:2532-2548. doi:10.1117/1.1503346.

Herrera-Ramírez, J., Vilaseca, M., and Pujol, J. 2014. Portable multispectral imaging system based on light-emitting diodes for spectral recovery from 370 to 1630 nm. Applied Optics, 53:3131-3141. doi:10.1364/AO.53.003131.

Kaye, T.G., Falk, A.R., Pittman, M., Sereno, P.C., Martin, L.D., Burnham, D.A., Gong, E., Xu, X., and Wang, Y. 2015. Laser-Stimulated Fluorescence in Paleontology. (C.M. Aegerter, Ed.)PLOS ONE, 10:e0125923. doi:10.1371/journal.pone.0125923.

Kaye, T.G., Martin, L., Burnham, D., and Gong, E. 2010. Multispectral Imaging and Analysis of a Liaoning "Mystery Specimen," Seventieth Annual Meeting of the Society of Vertebrate Paleontology, Pittsburgh, Pennsylvania.

Kubik, M. 2007. Hyperspectral imaging: a new technique for the non-invasive study of artworks. Physical Techniques in the Study of Art, Archaeology. Retrieved March 7, 2013, from www.sciencedirect.com/science/article/pii/S1871173107800078.

Marengo, E., Manfredi, M., Zerbinati, O., Robotti, E., Mazzucco, E., Gosetti, F., Bearman, G., France, F., and Shor, P. 2011. Technique based on LED multispectral imaging and multivariate analysis for monitoring the conservation state of the dead sea scrolls. Analytical Chemistry, 83:6609-6618. doi:10.1021/ac201068s.

Marigó, J., Minwer-Barakat, R., and Moyà-Solà, S., 2011. New Anchomomys (Adapoidea, Primates) from the Robiacian (Middle Eocene) of northeastern Spain. Taxonomic and evolutionary implications. Journal of Human Evolution, 60:665-672.
Minwer-Barakat, R., Marigó, J., and Moyà-Solà, S., 2010. A new species of Pseudoloris (Omomyidae, Primates) from the middle Eocene of Sant Jaume de Frontanyà (Eastern Pyrenees, Spain). American Journal of Physical Anthropology, 143:92-99.

Padoan, R., Steemers, T., Klein, M., and Aalderink, B. 2008. Quantitative Hyperspectral Imaging of Historical Documents: Technique and Application. ART Proceedings, 25-30. Retrieved from www.ndt.net/article/ art2008/papers/097Padoan.pdf.

Paquit, V.C., Tobin, K.W., Price, J.R., and Mériaudeau, F.M. 2009. 3D and multispectral imaging for subcutaneous veins detection. Optics express, 17:1136011365. Retrieved May 7, 2014, from www.opticsinfobase.org/oe/fulltext.cfm?uri=oe-17-14-11360.

Sala-Burgos, N. and Gil-Pita, R. 2006. Automatic microfossil detection in Somosaguas Sur paleontologic site (Pozuelo de Alarcón, Madrid, Spain ) using multilayer perceptrons. Wseas Transactions on Signal Processing, 2:218-223.

Shrestha, R., Hardeberg, J.Y., and Mansouri, A. 2011. One-shot multispectral color imaging with a stereo camera, Proceedings SPIE7876 Digital Photography VII. doi:10.1117/12.872428.

Tran, C.D. 2005. Principles, Instrumentation, and Applications of Infrared Multispectral Imaging, An Overview. Analytical Letters, 38:735-752.

Vandenberghe, N., Hilgen, F.J., and Speijer R.P. 2012. The Paleogene Period, p. 855-921 In Gradstein, F.M., Ogg, J.G., Schmitz, M.D., and Ogg, G.M. (eds.), The Geologic Time Scale 2012. Elsevier, Oxford.

Van den Hoek Ostende, L.W. 2003. Fossils explained 42. Micromammals. Geology Today, 19:70-76. doi:10.1046/j.1365-2451.2003.00391.x.

Vilaseca, M., Mercadal, R., Pujol, J., Arjona, M., de Lasarte, M., Huertas, R., Melgosa, M., and Imai, F.H. 2008. Characterization of the human iris spectral reflectance with a multispectral imaging system. Applied Optics, 47:5622-5630.

Vilaseca, M., Pujol, J., Arjona, M., and de Lasarte, M. 2006. Multispectral system for reflectance reconstruction in the near-infrared region. Applied Optics, 45:4241-4253.

Weng, Q. 2011. Advances in Environmental Remote Sensing: Sensors, Algorithms, and Applications. CRC Press, Boca Raton. 